\title{
A study on the user needs in sciences and medicine in the library of Universiti Brunei Darussalam: with a view to improving its services
}

The Author

\section{Perera, PASH}

B.Sc(Hons.)(Peradeniya), M.Phil(Peradeniya), MA(London), Pg.Dip(London)

Senior Assistant Libranian, Medical Library, University of Peradeniya

\section{Abstract}

This paper presents a part of the study that was carried out in the library of University Brunei Darussalam to assess the user needs in Sciences and Medicine. The main focus in this paper has been on the part of the study relating to services of the library. The targeted users were undergraduates, postgraduates and academic staff of the Faculty of Science and Institute of Medicine. Survey method included interviews and a hardcopy questionnaire that was administered during the first semester of 2005/2006. Data obtained through the questionnaire were coded and subjected to ANOVA, Descriplive statistics and Cross-tabulation using SpSS Version 12. Findings revealed

\footnotetext{
'An article on the first part of this studv has heen submitted for publication in the 2007 issue of the Sri Lanka Library Record.
} 
that the users who participated in the survey, while showing their satisfaction in some aspects, expressed concern about several other issues relating to the library services.

\section{Introduction}

The University Brunei Darussalam is a relatively young university which was established in 1985. Today the University accommodates more than 300 academic staff and 2,800 students in seven faculties, namely Arts and Social Sciences, Business, Economics and Policies Studies, Sultan Haji Omar Ali Saifuddien Institute of Islamic Studies, Science, Sultan Hassanal Bolkiah Institute of Education, Academy of Brunei Studies and Institute of Medicine. The major functions of the University Brunei Darussalam (UBD) are teaching, learning, research and community service.

The Library is literally the 'nerve centre' of the University as it is situated in a central location to all the faculties. It functions as a fully automated library equipped with modern facilities and comprises of a collection of books and other materials (including audio-visuals and electronic resources) nearing 400,000 volumes and a collection of 254 titles of journals. Its total membership of 4220 includes academic staff (majority being expatriates), postgraduates and undergraduates (inciudes foreign students), administrative staff and general public as external users,

It is inevitable that user behaviour and expectations in any library to through significant changes due to the altered information environment in today's world. Due to this reason library user surveys have become widespread in academic libraries and have often been used as a tool to assess service quality and user needs and user satisfaction. The author during her sabbatical year as a research fellow at UBD library carried out the present study and it is an attempt to evaluate the user needs in Sciences and Medicine of the library. Instead of embarking on a survey in mass scale involving entire university community it was decided to evaluate user needs 
of the library only in the areas of Sciences and Medicine. The reason for this decision was mainly due to the rapid expansion of the knowledge base in these two inter-related fields than in any other discipline. Although the membership of the library includes administrative staff and external members as well, it was decided to focus only on the three user groups: academic staff, undergraduates and postgraduates of the Faculty of Science and Institute of Medicine of the university. All aspects of the library services except community services were investigated in the survey. Community services are more dealt with external membership including generat public. Objectives of the study are to identify needs of the targeted library users in the Sciences and Medicine; to determine the extent of satisfaction of these users with reference to the different services offered by the library; to identify the deficiencies, as viewed by the users, and thereby to improve the quality of services offered by the Library.

For the purpose of this article, only the part of the survey that dealt with user needs in terms of library services will be discussed

\section{Methodology}

A literature survey on previous studies on assessing user needs of the library at UBD and elsewhere was carried out. Some reports on surveys carried out to investigate user needs in university libraries are found in literature ${ }^{2-5}$. Due to the sample size chosen for the present study, a paperbased survey instrument; a hardcopy questionnaire was deemed most appropriate. It was decided to hold prior interviews with selected users to collect preliminary information before construction of the questionnaire. Twenty five academic staff members and six undergraduates were picked randomly and were interviewed to collect information on their needs and expectations as users of the library. Interviews were held during the period 30/06/05-30/07/05. Prior appointments were obtained from the academic staff for interviews that lasted for 20-30 minutes. The academic staff 
members were selected to represent all the departments of Faculty of Science and Institute of Medicine. The same set of questions was asked from each user. Undergraduates were randomly selected for interviews while they were in the library. Interviews were transcribed. The information in the interview transcripts were later reviewed and classified in order to identify the various issues to be addressed in the questionnaire.

The survey was carried out during September 2005, which was the first semester of the academic year 2005/2006 in UBD. A pre-notification of one week was given through e-mail to academic staff regarding the survey before leaving the questionnaire in the pigeonhole of each member. The Questionnaires were handed over personally to all the postgraduates. With the permission and cooperation of the academic staff members in charge, the questionnaires were administered to undergraduates during their classes just before a lecture or a practical class and collected it after the class, allowing them about 15 minutes to answer the questionnaire.

\section{Survey instrument:}

Based on the information gathered from the interviews, the questionnaire was designed to obtain the information pertaining to the following:

- Importance and awareness of the library services

- Frequency of library use,

- The library collection, relevance of library materials, use of electronic resources, ease of access,

- What documents are most important,

- Unmet needs

- How satisfied the users are about the library staff,

- Effectiveness of the facilities and the users' perception of environment etc. 
A demographic component also was included in the questionnaire.

The questionnaire consisted of twenty-two main questions and several subsidiary questions, which were all close-ended. Provision was, however, made at the end of questionnaire for the respondents to provide their views, as free text comments and suggestions, on any aspect of the library. Many respondents used this opportunity to express their views on the library.

The same questionnaire was administered to all three user groups. Respondents were asked to tick off an appropriate box in all the closeended questions. Adequate space was provided for respondents to write comments. A covering letter was attached to the questionnaire explaining the objective and the purpose of the study.

\section{Sample:}

Due to the small size of user groups in certain subject areas of Faculty of Science and Institute of Medicine, it was decided to use the entire student and academic staff population as samples for the study. As such, all 8 academic staff members from the Institute of Medicine and 75 academic staff members from the Faculty of Science were included in the study. The questionnaire was administered to 280 students from Faculty of Science and 7 students from the Institute of Medicine. First year undergraduates were excluded from the survey due to the very short period of their library use. Only the second, third and fourth year undergraduates were included in the survey. All eight postgraduates that the researcher could contact at the time of the survey participated in it. All of them were from the Faculty of Science. About 20 other postgraduate students had already left the university after completion of their studies just prior to the administration of the questionnaire. 


\section{Survey response and representativeness:}

The response rate of the survey for each category is shown in the Figure 3.2 (in Section 3.2). The percentage of respondents in the category of undergraduates is much higher than the other categories. This is perhaps due to the manner in which the questionnaires were administered and collected (during a practical class or a lecture). Thus it is seen that the percentage of respondents in the undergraduate group well represented the population in this category while the percentage of respondents in the academic staff can be considered as a reasonable representation of the group. Due to the fact that a majority of the postgraduate students who have been using the library were not available for the survey, it was inevitable that the group was under-represented by its survey respondents. The Institute of Medicine has a small population of both staff and students. And as such the subject samples for the survey were very small. There were no postgraduate students in the Institute of Medicine.

\section{Statistical analysis:}

Responses received through the questionnaires were categorised, coded and entered in the computer for use in statistical analysis ${ }^{7,8}$. The data thus obtained, were analysed using the software package SPSS (version 12). Normal distribution curve was plotted for data relevant to each question, before deciding on the appropriate statistical analytical procedure. Consequently, analysis of variance (ANOVA) with LSD, Bonferroni corrections and Post Hoc Test, and Cross-tabulation procedures were carried out with each question as appropriate. 


\section{Survey results and major findings}

For the purpose of the article survey results pertaining only to library services will be discussed here.

\section{Interviews:}

The following is a synopsis of the views presented and comments made by the respondents belonging to different categories during the interviews.

- Majority of the academic staff members who were interviewed stated that they were not satisfied with the present library facilities. All six undergraduates who were interviewed were somewhat satisfied with the present set-up with reservations in some areas.

- All 25 academic staff members had similar opinions about the usefulness of the online databases. They appreciated the fact that the library is taking steps to improve the collection of on-line resources. However, they were not satisfied with the subject coverage of the available on-line databases and about the connectivity. In addition, they requested for awareness programmes to educate the users about available electronic resources in Medicine.

- Academic staff members of the Institute of Medicine commended on the database OVID; however, they complained about the accessibility of the databases. At present the system allows only two users at a given time, which is not satisfactory.

- Problems/suggestions regarding library matters:

Some of the more frequent comments made by the survey sample are listed below 
- Use of online facilities is hampered by the poor connectivity of the university network (system is very slow). As such, usage of Internet is very limited. This situation has affected the research activities of faculty of science immensely.

- Inter-library-loan system needs to be improved, as it is a very slow process. It takes a very long time to receive articles requested through this system.

- All the staff members suggested that the library should cater to research needs of the university.

- The electronic system of the library lacks effective searching facilities.

- Information displayed on certain queries regarding library transaction is not correct.

- A few glances at any shelf in the book collection will reveal books that are misplaced. Insufficient care is taken when re-shelving books and no casual checks of the stacks are carried out to correct this.

- It takes a long time to receive a book that has been ordered through the library.

- Books on long-term loan cannot be renewed on-line. It is a waste of time to bring all the books to the library only for renewal.

- Library takes a long time to re-shelve the returned books; therefore, one cannot find certain books on the shelves despite OPAC indicating their availability.

- Curriculum resource room is disorganized. Finding books there is difficult.

- Students can only borrow books for two weeks, which discourages some of them from borrowing at all, since they have to choose between carrying renewals around them every few days, or risking overdue book fines. The loan period should be one-month minimum. 


\section{Questionnaire - Main findings in summary:}

The total number of questionnaires administered to three categories of user groups, undergraduates, postgraduates and academic staff were 378 in total. The response rates of different categories are shown in Figure 3.2.

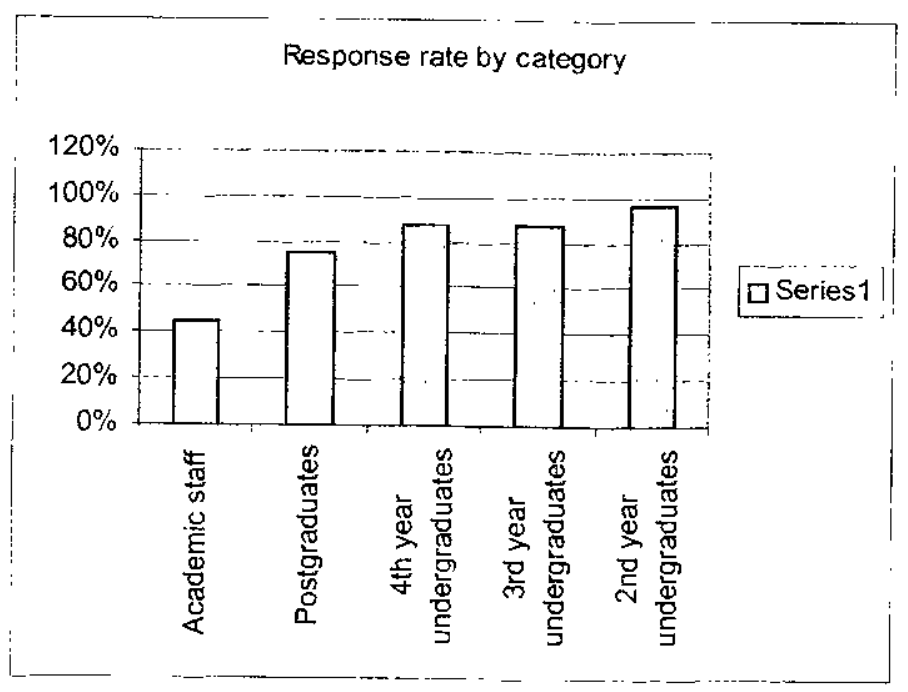

Figure 3.2. Response rate by category of the user group.

Analysis of coded data using SPSS revealed that total number of respondents were 300 while $86 \%$ of this represented undergraduates, $2 \%$ postgraduates and $12 \%$ represented academic staff. In the Faculty of Science though the number of postgraduates was 25 , at the time of the survey, many of them had just left the faculty after completion of the course. Due to the very small sample number, it will be difficult to reach any general conclusions regarding the user needs of postgraduates from this study. As such, the study was focused mainly on undergraduates and academic staff.

The number of respondents was not large enough specially for academic staff and postgraduates to examine the degree of variation within groups by 
subjects and for undergraduates within groups by class year. Further it was not attempted to examine the variations among demographic characteristics. A summary of the findings of the data analysis is given under the theme of each question in the following section. A detailed breakdown of the analysis of the survey results is available to interested parties on requested from the author.

\section{Average frequency of library usage by the readers}

Responses to this question were analysed in two different ways; by profession (whether staff or student) and by whether or not expatriate or local lecturer/student.

Analysis of data with ANOVA showed that there was a significant difference in the pattern of the library usage by the three user groups mainly between undergraduates and academic staff ( $P$ value at 0.000 and $F_{2,233}=16.751$ ). The mean values of the responses lied at 'once a week' for undergraduates and at 'Once in two weeks' for postgraduates and academic staff. Nearly $67 \%$ of postgraduates have used the library only once a month. However, due to the fact that only very small sample of population was surveyed in this user-group (postgraduates), the results would not support any concluding remarks.

There was a variation in the pattern of library use, between expatriate lecturer/student and local lecturer/student. The mean value of the responses was more towards the latter between 'once a week' and 'once in two weeks' for expatriate lecturers and at 'once a month' for local lecturers. According to the results of the analysis of data with ANOVA the difference in mean values implied a significant difference at the level $P=0.05$, in the pattern of the usage of the library by expatriate and local lecturers. The 
mean value of the responses of the students showed that it was at conce a week' for both local and foreign students but more towards 'once in two weeks'. However the statistics revealed that there was no significant difference in the pattern of usage of library between these two groups.

\section{Library facilities for teaching/learning activities}

None of the academic staff or postgraduates has selected 'very satisfied' in answering the question, except for $4 \%$ of the undergraduates. The comparison of mean values of the responses showed that the mean value was at 'satisfied' for undergraduates and postgraduates whereas it was slightly shifted towards 'neutral' for academic staff. However, the results of the analysis showed that there was no significant difference in the mean values between these three groups which revealed that overall the users surveyed were satisfied with the library facilities with respect to teaching and learning. The data was compared between, local students and foreign students and between local lecturers and foreign lecturers. The results showed no significant difference between the groups.

\section{Library facilities for research activities}

Comparison of mean values of responses implied that there was a significant difference at $P=0.05$, between the undergraduates and the academic staff in their perception over this question, with mean values falling at 'satisfied' and 'neutral' respectively.

The data was compared between expatriate and local membership. Comparison of the mean values of the responses revealed that there was no significant difference in the mean values between expatriate and local lecturers where mean value was at 'neutral'. Similarly, there was no 
significant difference in the mean values between expatriate and local students with a mean value at 'satisfied'.

\section{Inter-Library Loan service of the library}

Total of 62.6 percent of undergraduates and total of $40 \%$ of academic staff considered the service as useful. Out of this, $29 \%$ of academic staff commented that the service was very slow. Nearly $15 \%$ of the academic staff found it useless. In the statistical analysis, ANOVA and Post Hoc Test showed that there was no significant difference in the mean values of responses between the three user groups. The mean values were between 'useful' and 'useless' for all users.

\section{Ordering procedure of library materials}

Comparison of means of the respondents revealed that the mean value of the responses were between 'not satisfied' and 'needs improvements'. As indicated in the interviews, the main problem was the long delay in the procedure of ordering library materials, which took a long time to receive a requested book.

\section{Borrowing and returning service of the library}

Post Hoc Test of ANOVA showed that there was a marginal difference in the mean values of responses between academic staff and undergraduates with $P=0.06$. The mean value for academic staff was in the middle between 'satisfied' and 'not satisfied ${ }^{z}$ while that of undergraduates was more towards 'not satisfied' in the same range. Therefore these statistics indicated that there are problems faced by the undergraduates relating to borrowing/returning service of the library. 


\section{Whether or not Online-Public Access Catalogue (OPAC) was used to access líbrary materials}

Analysis with ANOVA showed that there was a very significant difference (at level 0.05 ), in the mean values of the responses between undergraduates and academic staff as well as between postgraduates and undergraduates with $P=0.000$ and $F_{2,290}=8.794$. Mean value of the responses of academic staff was at 'yes' while that of postgraduates and undergraduates was between 'yes' and 'no'. It is surprising to note that $32 \%$ of academic staff did not use the OPAC to access library materials.

\section{Electronic operating system of the library}

Cross-tabulation analysis of data revealed that only very small percentages of the users selected 'very satisfied'. To a certain degree of percentage, undergraduates and academic staff were not satisfied. Comparison of means showed that the mean value for academic staff was at 'neutral' while that of undergraduates and postgraduates was between 'satisfied' and 'neutral'. However, analysis using Post Hoc Test in ANOVA revealed that there was no significant difference in the mean values between the three user groups.

\section{Services at the reference desk}

Cross-tabulation analysis of data revealed that only very small percentages of the users selected 'very satisfied'. Comparison of means of the responses showed that the mean values for all three user groups were between 'satisfied' and 'neutral'. Analysis of data using Post Hoc Test in 
ANOVA revealed that there was no significant difference in the mean values between the three user groups

\section{Services at the circulation desk}

Cross-tabulation analysis of data revealed that only very small percentages of the users selected 'very satisfied'. Comparison of means of response showed that the mean values for all three user groups were between 'satisfied' and 'neutral'. Analysis of data using Post Hoc Test in ANOVA revealed that there was no significant difference in the mean values between the three user groups.

\section{Current awareness service}

Comparison of means of responses using Post Hoc Test in ANOVA showed that there was no significant difference in the mean values between the three user groups. The mean score for all three groups was more towards 'satisfied' between 'satisfied' and 'neutral'.

\section{Availability of computer terminals}

Gross-tabulation analysis of data revealed that majority of the academic staff and undergraduates selected 'neutral' or 'not satisfied' as the answer to this question. However, comparison of means of the responses showed that the mean values for all three user groups were at 'neutral'. Analysis of data using Post Hoc Test in ANOVA revealed that there was no significant difference in the mean values between the three user groups. 


\section{Library hours}

Comparison of means of the responses using Post Hoc Test in ANOVA showed that there was no significant difference in the mean values between the three user groups and that the mean value lies at 'satisfied'

\section{Selected free comments made by the respondents at the end of questionnaire about the librery services/facilities}

\section{Library services and procedures:}

"Ordering procedure took a long time to process the application".

"Even for Super Rush order, it takes more than a week".

"Inter-library-loan service is very slow, hence awfully useless".

'The money spent on books is not economical; we are paying too much for books. I

can get the same books for less money."

"Extend the duration of book loans."

"Require the OPAC to work efficiently and properly."

"Reduce the fine on overdue books."

"Re-shelve the returned books efficiently".

"Borrowing section is very inefficient. It should be possible to renew books online,

so that we don't have to carry heavy books to the library only to renew."

"Library should be fair enough to allow us at least a week from the due date to renew books, before suspending us from borrowing." 


\section{Overall satisfaction/problems:}

"Announcements of library system breakdown should be efficiently circulated through the university."

"Even after refurning the book, the computer system indicates that it is not. This is incompetency of the staff and they do not look for the book, instead get us to do it, wasting our valuable time."

"Automatic checking out system is very inadequate and unreliable. When students are in a rush to check out and the automated system is full, the librarians are not willing to do the checkout and this is unacceptable."

"From now on I don't trust the Book Drop. Because I was told that I didn't returned the book, which I remember I retuned. I had to pay double the cost for this book and it was a lot of money. "

\section{Suggestions:}

"System of borrowing books should be improved".

"Library operations can only be improved through discussions with academic staff and student representatives".

"Give a specific room for students to use their laptops."

"Increase the number of photocopying machines"

"Provide open area for group discussion".

"Need educational channels of the TV on the ground floor."

"Library should open on Fridays and Sundays."

“Longer library hours till 10.00p.m. Please". 


\section{Final Comments}

The percentages of users from categories of undergraduates and academic staff responded to the survey were deemed sufficient to reach reasonable conclusions on the underlying populations. However, due to the very small numbers of the total student and academic staff population in the Institute of Medicine, it was not possible to distinguish the pattern/extent of user needs between Medicine and Sciences.

Findings indicated that undergraduates used the library more often than postgraduates and academic staff. Similarly, expatriate lectures used the library more often than local lecturers. Overall the users surveyed were satisfied with the library facilities with respect to teaching and learning activities. Academic staff was not satisfied with the facilities available for research purposes; therefore, facilities for research should be improved. Users those were surveyed rated the Inter-Library-Loan-Service between 'Useful' and 'useless' which is an indication of dissatisfaction; thus ILL service should be improved. Ordering procedure of the library materials seems to be very slow thus needs improvements. As commented in the interviews and in the questionnaire, undergraduates were not happy with the borrowing and returning service and through their responses to the questionnaire it revealed that there are problems faced by the undergraduates relating to borrowing/returning service of the library. Majority of the users showed satisfaction over the present library hours though free comments in the questionnaire included requests for longer library hours extending to weekends. Users' response regarding electronic operating system, services at the reference desk and services at the circulation desk has been at a low satisfactory level as the mean value lies between 'satisfied' and 'neutral'. Users regarded inadequate number of computer terminals as a problem. Some of these issues were pointed out as free comments as well in the questionnaire, on which the library 
authorities should pay their attention. It is recommended that these issues are appropriately addressed and monitored periodjcally.

It is finally recommended that surveys similar to this be carried out to study the user needs of the undergraduates and the academic staff of other faculties in UBD in order to identify the needs of the entire University community with a view to further improve the services offered by the Library.

There were several limitations in carrying out the study. Most of the postgraduates were not available during the time that the survey was carried out. As such this important user category was underrepresented in this study. Therefore, the needs of this category of users could not be ascertained. Undergraduates were given only 10-15 minutes to respond to the questionnaire and this time constraint might have affected the answers given by them. Fifty five percent of academic staff did not respond to the questionnaire even after several reminders. A higher rate of response from this category would certainly have improved the representativeness of the views of this important group of users.

\section{References}

A study on the user needs in Sciences and Medicine in the library of Universiti Brunei Darussalam, with a view to improving its collection of library materials, P.A.S.H.Perera, Paper submitted for publication, Sri Lanka Library Record, 2007

Foster, Jeremy, J. (2002), Data analysis using SPSS for Windows version 8 to 10: A beginner's guide, Sage Publications Ltd., London. 
Hayden, Helen ; O'Brien, Terry; \& Rathaille, Maoiliosa O (2005)User Survey at Waterford Institute of Technology Libraries: How a traditional approach to surveys can inform library service delivery. New Library World, 106(1208/1209), 43-57.

Hiller, Steve.(2001).Assessing User Needs, Satisfaction and Library Performance at the University of Washington Libraries. Library Trends, 49(4),605.

Line, Maurice, B.(1982), Library surveys: An introduction to the use, planning procedure and presentation of surveys, $2^{\text {nd }}$ edition, Clive Bingly, London.

Powell, Roland, R.(1997), Basic research methods for librarians, $3^{\text {rd }}$ edition, Alex Publishing Corporation, London

Stephen, Peter and Hornby, Susan.(1995), Simple statistics for library and information professionals, Library Association Publishing, London.

UCSD Libraries - Undergraduate Survey(1996) ; Library Research Service, Research and Statistics about Libraries. www.Irs/usersurveys.asp 